\title{
LAS REDES CLIENTELISTAS EN LOS MÁRGENES DE ESTADO.
}

NETWORKS OF PATRONAGE IN THE MARGINS OF THE STATE.

Recibido: Noviembre de 2011 - Revisado: Febrero de 2012 - Aceptado: 30 de Mayo de 2012

Por: Marisol Tarapues Taimal ${ }^{1}$.

\section{RESUMEN:}

Este artículo de investigación pretendo abrir un debate empírico y teórico sobre el clientelismo como característica de la debilidad del Estado en América Latina y en Colombia.

\section{PALABRAS CLAVE:}

clientelismo, América latina, descentralización política.

\section{ABSTRACT:}

This research article aims at opening the empirical and theoretical debate on patronage as a feature of the weakness of the State in Latin America and Colombia.

\section{KEY WORDS AND EXPRESSIONS:}

Patronage, Latin America, Political decentralization.

\footnotetext{
${ }^{1}$ Socióloga. Universidad del Valle - Colombia, Investigadora Facultad de Ciencias Sociales y Económicas. mary.pastos@univalle.edu.co;mary.pastos@gmail.com
} 


\section{Introducción.}

Los Estados latinoamericanos son "débiles", esa es la conclusión a la que llega O` Donnell (2004; 2007) al analizar el estado de la Democracia en América Latina. De acuerdo a este análisis hay tres aspectos de la debilidad de los Estados: La ineficacia en el conjunto de sus burocracias, la poca efectividad del sistema legal y la poca credibilidad como ejecutor del bien común. Para O`Donnell (2007: 65) el gran problema del Estado en Latinoamérica:

"en el pasado, y aún en un presente en el que los regímenes democráticos predominan, es que, con pocas excepciones, no penetra ni controla el conjunto de su territorio, ha implantado una legalidad frecuentemente truncada y la legitimidad de la coerción que lo respalda es desafiada por su escasa credibilidad como intérprete y realizador del bien común".

Estas características de la debilidad de Estado fueron analizadas y fuertemente debatidas en los diferentes estudios latinoamericanos y colombianos que se han concentrado en el análisis del clientelismo político. Como también, han sido objeto de debates teórico-analíticos alrededor del clientelismo político, la democracia, la ciudadanía y la formación de Estado.

Estudios latinoamericanos.

A pesar de la democratización de los países latinoamericanos, el clientelismo ha sobrevivido y continúa siendo objeto de análisis de las ciencias sociales. En esta sección tomaré tres estudios latinoamericanos realizados en México, Chile y Argentina, que serán posteriormente contrastados con la propuesta teórico-metodológica de red clientelista. El primero se titula: "Clientelismo, patronazgo y justicia electoral en México: Una lectura institucionalista" realizado por Jorge Romero en conjunto con el PNUD- México (2007: 1-34). En este estudio se muestra un enfoque político-cultural del clientelismo, orientado principalmente al análisis institucional del clientelismo en México y su desarrollo en un "Estado débil». Para Jorge Romero (2007), el clientelismo y el patronazgo son prácticas fuertemente institucionalizadas a partir de la combinación de prácticas ancestrales (patronazgo) y las nuevas tecnologías sociales; es decir, es una "mezcla compleja de reglas y modelos sociales con mapas mentales de los politicos quienes tradicionalmente asociaron la extensión de su fuerza con la distribución de prebendas y favores, protecciones particulares y ventajas distributivas y con un sistema de incentivos provisto por el Estado, que extendia su dominio gracias al sistema de intermediaciones y solución de conflictos que le proporcionaba la red clientelista"(Ibíd., 2007: 5).

El clientelismo implica para Romero la existencia de una gran maquinaria de intermediación politica, que involucra a las personas en una relación de reciprocidad asimétrica y un manejo de los bienes públicos con fines privados y excluyentes. Este estudio da cuenta de lo adaptable que es el clientelismo como forma de vida cultural, política y económica; pues a pesar de las reformas hechas en México en 1996, la institución del patronazgo que utilizaba sus propios recursos económicos y de lealtad, se configura ahora como un clientelismo político-económico que puede hacer uso de los recursos económicos ofrecidos por el Estado. Esta maquinaria de intermediación política implica claramente una débil presencia institucional y legal del Estado. 
En el segundo estudio, "El clientelismo politico en el campo chileno" realizado por John Durston (2005: 1-30). Se reconoce que el clientelismo sigue vigente en los diversos contextos de modernidad, además el autor propone aspectos importantes sobre las estrategias de los mediadores o Brokers para mantener el control en el acceso a los recursos estatales y su posicionamiento de poder. Entre las estrategias de los mediadores se encuentran: modificar los diseños formales de los programas, proyectos y concursos de desarrollo rural asociativo, el reclutamiento de las redes de cooperación y asociatividad de las comunidades campesinas, y la monopolización de la información. El enfoque económico de este estudio permite entender al Bróker como un "operario económico que articula un número de demandas particulares con un mercado mayorista" (Ibíd., 2005: 7). Para Durston es importante reconocer el uso privado de recursos públicos por parte del mediador, puesto que implica que los recursos estatales están brindando la base económica para el desarrollo del clientelismo. También destaca la importancia del capital social en el desarrollo del clientelismo, entendido como la vinculación de redes de cooperación o ayuda mutua entre los campesino chilenos a las redes politicas. Sin embargo, si el capital social no es activado en una red de relaciones, éste se vuelve ineficaz. Y por tanto, es dificil entender el clientelismo si los recursos del capital social no son activados en una red de relaciones.

Finalmente el estudio de Javier Auyero, "La politica de los pobres: las prácticas clientelistas del peronismo" (2001: 1-251) ofrece una descripción detallada de la incorporación de las redes de resolución de problemas en las redes políticas: en las que se suministra, reconfigura y refuerza un conjunto de prácticas materiales y construcciones simbólicas que constituyen un principio organizador social. Por tanto el clientelismo "no sólo es una institución informal sino también un sistema simbólico; una estructura estructurante, dando sentido a la experiencia de la pobreza en un lugar y en un tiempo determinados” (Ibíd., 2001: 43). Este enfoque cultural del clientelismo permite observar la relación entre las redes políticas y las redes de resolución de problemas; no como meros intercambios políticos o intercambios económicos (favores por votos) sino como un intercambio de lazos sociales (reciprocidad mutua) que configuran el mundo de las prácticas y el mundo de lo simbólico.

Para Auyero, "el intercambio de favores por votos en el centro de la noción de clientelismo politico no representa adecuadamente esta realidad mucho más compleja de relaciones duraderas, narrativas e identidades que son construidas en el funcionamiento diario de los círculos intimos" (Ibíd., 2001: 230). Finalmente, esta mediación política no es un proceso evidente sino un conjunto de relaciones, con sus propias reglas, sus silencios, sus voces, sus trayectorias que se configuran entre las redes sociales y se ponen en práctica entre sus participantes: politicos, mediadores y clientes.

\section{Metodología.}

Este es un estudio de referentes empírico-teórico: respecto a los estudios empíricos, se destaca el hecho de que a pesar del proceso de democratización en los países latinoamericanos, el clientelismo sigue siendo una figura predominante en los contextos políticos. Sobre todo en el caso colombiano, donde la descentralización política y fiscal permitió que surgiera un nuevo tipo de intermediación política sustentada en la economía de 
Estado. Por otro lado, la disertación teórica sobre el clientelismo estará basada en las perspectivas económica, política y cultural, para finalmente proponer el modelo teórico de red clientelista que permita identificar las conexiones politicas entre el patrón, cliente y mediador.

\section{Resultados y discusiones.}

Estudios colombianos.

El clientelismo político también ha sido objeto de análisis en Colombia. Los aportes de los estudios interdisciplinarios emprendidos en las últimas décadas dan cuenta de las singularidades de la democracia y el Estado colombiano. En estos estudios persisten las ideas de debilidad institucional del Estado, la poca efectividad del sistema legal y el poco control territorial. Para objetivos de mi investigación, escogí cuatro estudios sobre el clientelismo político y un estudio de contexto político- económico en los 25 años de descentralización en Colombia.

Entre los estudios clásicos se destaca la obra de Fernando Leal y Andrés Dávila, "Clientelismo, el sistema politico y su expresión regional" (1991: 1-382). En este estudio se explora la organización de una maquinaria electoral y la eficiente adecuación de las relaciones políticas a la estructura institucional. Su análisis se centra en las coyunturas electorales, donde el intercambio de favores por votos se hace más evidente y donde se legitiman electoralmente estos procesos. Los autores hacen un paralelo de tipos de clientelismo y dos tipos de líderes políticos, que al mismo tiempo corresponden a dos momentos históricos. El primero corresponde a un clientelismo tradicional con predominio de un partido y un jefe político, que por lo general imponen relaciones basadas en el antiguo y difundido valor de las lealtades personales para el mantenimiento de sus clientelas. Principalmente los líderes políticos en este tipo de clientelismo eran propietarios, maestros, comerciantes, e intelectuales que mantenían un prestigio y legitimidad anterior al liderazgo su poder era de carácter regional y nacional-. Por el contrario, en el clientelismo de mercado no hay predominio de un jefe político, sino la proliferación de nuevos políticos que carecen de prestigio y de recursos propios y por lo tanto, necesitan de los recursos oficiales para su movilidad social y a través de relaciones articuladas en una red vertical sobre la base de intercambio de favores -su poder es de carácter local-. Para los autores la debilidad política del Estado y la base económica prestada por el mismo, ha permitido que el clientelismo se traslade a lo local y que éste asuma un papel articulador en una sociedad marcada por la poca presencia del Estado.

Siguiendo este mismo modelo de análisis, la investigación de Mauricio García y Javier Rebelo "Estado alterado: clientelismo, mafias y debilidad institucional" (2010: 1-239) considera que el clientelismo está en contravía al Estado derecho. Su hipótesis básica es que la debilidad institucional del Estado colombiano ha permitido el aumento de relaciones clientelares, su captura y la reconfiguración cooptada de sus instituciones por parte de mafias locales y regionales. Para los autores "la falta de sintonía entre territorio, economía e institucionalidad da lugar a una presencia diferenciada no sólo del Estado sino de los actores sociales que actúan en cada zona con estrategias y comportamientos distintos" (Ibíd., 2010: 19). Para Villegas y Revelo, cuando el Estado es incapaz de hacer presencia en lo local, surgen 
intermediarios que cumplen ciertas funciones de regulación, legitimación y orden a nivel local. Esta situación se convierte en un escenario perfecto para el clientelismo y la captura institucional del Estado, sobre todo en aquellos municipios alejados y afectados por el conflicto armado. No obstante, este estudio es interesante porque presenta cuatro razones por las que el clientelismo ha transcendido de obtener favores y repartir recursos, a perseguir la captura de las instituciones e incluso la reconfiguración cooptada del Estado.

En sintesis, la sociabilidad clientelista crea, refuerza y promueve las sociabilidades tradicionales, en base a que: 1) "La administración pública ha sido incapaz de controlar todo el espacio que le corresponde a su jurisdicción" y por tanto delega las funciones públicas a poderes locales; 2) El clientelismo es "fuente de justicia distributiva" siendo "un escape de las clases subordinadas para tener recursos y acceso al poder"; 3) Ante el déficit de regulación social y de democratización el clientelismo es una "herramienta para la negociación en entornos conflictivos"; y 4) es "un dispositivo para aliviar las tensiones entre lo legal y lo ilegal" propiciando un mundo social basado en las clientelas y la ley (Ibíd., 2010: 30-33). Para los autores la captura del Estado se debe a los efectos de la política de descentralización, que fue introducida en un contexto pre-moderno caracterizado por el clientelismo, el gamonalismo y el narcotráfico.

Acercándome más al objetivo de mi disertación, el estudio de Eugenia Meneses "la politica nasa y el clientelismo: en el municipio de Páez, Cauca" (2002: 105-130) ofrece una descripción de los procesos políticos, culturales y económicos en una comunidad indígena posteriores a la constitución de 1991 y las transferencias de recursos a los resguardos indígenas. Según Meneses la entrada de recursos al cabildo después de 1994, ha permitido la formación de redes clientelares, fundamentadas en las posiciones de poder que empezaron a desempeñar algunos líderes en las organizaciones indígenas. Sin embargo estas redes clientelistas no tienen un sistema idéntico al practicado en los partidos políticos tradicionales.

El reconocimiento cultural y político de las comunidades indígenas en la constitución de 1991, les permitió establecerse como resguardos y cabildos, y posteriormente acceder a "la transferencia anual de dineros de la nación a los cabildos indígenas, que los han convertido en administradores de los recursos y a su gobernador en el representante legal de la comunidad con respecto a los mismos" (Ibíd., 2002: 118). Este acceso a los recursos transformó radicalmente las relaciones entre el Estado y las comunidades, colocando a los cabildos y sus gobernadores como intermediarios con cierta autonomía. Por otro lado, las relaciones entre los líderes indígenas y sus comunidades también cambiaron, las prácticas electorales se convirtieron en una pugna por los puestos burocráticos en el cabildo o la alcaldia, creando "un conjunto de nuevas relaciones de dependencia alrededor de grupos de personas que ocupan esas posiciones privilegiadas" (Ibíd., 2002: 120); es decir surgió un nuevo tipo de clientela. Según Meneses el control sobre los recursos ejercido por un grupo limitado de personas, se debe a que la sociedad del municipio Páez es poco diferenciada, y por tanto las elites son reducidas y tienen mayor poder de decisión. Sin embargo, en su estudio Meneses no analiza a profundidad la forma en que se desarrolla este clientelismo, y lo lee como la mayoría de los autores clásicos: como un intercambio interpersonal de bienes y servicios entre individuos de mayor status económico (patrón) y otros de menor status socioeconómico (cliente). 
Por lo tanto considero que es deficiente considerar al clientelismo como una relación diádica (patrón- cliente), pues el rol de los intermediarios y mundo de conexiones que genera este actor entre el político y el ciudadano, está siendo obviado.

Finalmente, el estudio de Margarita Chaves y Juan Felipe Hoyos, "El estado en las márgenes y las márgenes como estado. Transferencias económicas y gobiernos indígenas en Putumayo" (2011: 115-134), hace una aproximación a esa lógica de Estado que opera en unos márgenes poco controlados. Precisamente este estudio muestra esas prácticas de estatalidad desarrolladas al interior de los gobiernos indigenas ya sea a través de la apropiación en sus discursos de las políticas legislativas, el uso de tecnologías de gobierno (censos, mapas y reportes) y la administración de recursos fiscales (transferencias). Para Chaves y Hoyos, la política de transferencias y la autonomía de los entes territoriales de la nación departamentos, municipios y resguardos indígenas- convirtió a los gobernadores en "ordenadores del gasto sin regulación legal y les permitió decidir, según sus propios criterios, qué se hacía, quién lo hacía y cómo se hacia" (Ibíd.,2011: 119), generando un campo de prácticas de dos tipos: uno hacia la institucionalización, instauración de conocimiento experto (tramites y contratos) y otro hacia la desinstitucionalización, aparición de prácticas alejadas de la reglamentación institucional ( uso personalista de los recursos). Sin embargo, estos dos tipos de prácticas no son excluyentes, por el contrario, ofrecen vehículos de articulación "entre sujetos ubicados en diferentes espacios de poder, que permite el acceso a recursos y redes que de otra manera no estarian a su alcance y sin los cuales las posibilidades de gobernar serian nulas" (Ibíd., 2011: 130).

Las prácticas de estatalidad basadas en la institucionalización de formas legales y en desinstitucionalización por medio de empresas clientelistas, configuran un nuevo sujeto social en un complejo juego identitario. Por lo tanto, el proyecto de nación aplicado según "politicas fragmentarias, desconectadas en sus ámbitos normativo y ejecutivo y puestas en manos de múltiples funcionarios" (Ibíd., 2011: 131) conducen a una multiplicidad de actores con intereses particulares, que se construyen y constituyen en las márgenes de estado.

Descentralización en Colombia: Descentralización política y fiscal.

Finalmente para entender el contexto de los estudios colombianos sobre el clientelismo, debemos entender ¿cómo actuó la descentralización política y fiscal en ámbitos locales?, y ¿Qué alcances y limitaciones tuvo el proyecto descentralizador en Colombia? Primero, la descentralización redefinió las responsabilidades de gasto en todos los niveles de gobierno, modificando asi el sistema de transferencias del nivel central hacia los gobiernos municipales y departamentales.

La descentralización empezó entre los años 1983-1986 y fue avalada posteriormente en la constitución de 1991 por el artículo 287: "las entidades territoriales gozan de autonomía para la gestión de sus intereses (...). En tal virtud tendrán los siguientes derechos: 1. Gobernarse por autoridades propias, 2. Ejercer las competencias que le correspondan, 3. Administrar los recursos y establecer los tributos necesarios para el cumplimiento de sus funciones, 4. Participar en las rentas nacionales" (Gutiérrez; 2010: 17-18). Por otro lado la descentralización fiscal tomó eco en los artículos 356 al 364 del titulo XII, Capitulo 4, donde se creó el Fondo Nacional de Regalías, que reconoce como beneficiaria de las regalías a las "entidades

ra

AGO.USB Medellín-Colombia $\quad$ V. $12 \quad N^{\circ} 2 \quad$ PP. 214- 547 Julio-Diciembre 2012 ISSN: 1657-8031 
territoriales en las cuales se explotan y los puertos fluviales por donde se transportan los recursos naturales no renovables" (Ibíd., 2010: 18). Diez años después, en el 2001 mediante al acto legislativo 01, se modifican los artículos 151, 288, 356 y 357 (servicios a cargo de la nación y las entidades territoriales y la participación de los Ingresos Corrientes de la Nación) que establece parámetros y procedimientos de administración y ejecución de los recursos de transferencias a los resguardos y en el acto legislativo 04 de 2007, se "modificó el destino y asignación de los recursos del sistema general de participaciones, creando un sistema de monitoreo, seguimiento y control al gasto de las entidades territoriales" (Ibíd., 2010: 19).

Diversos analistas han evaluado el deterioro, las limitaciones y alcances del proceso de "descentralización". Entre las críticas se encuentran: a) el persistente déficit fiscal de la nación y su posible relación con las transferencias generadas por la descentralización, b) la inversión pública local sigue sin reflejar las prioridades, necesidades y posibilidades de las entidades territoriales, c) la corrupción en el manejo de los recursos de inversión y la debilidad o ausencia de un efectivo control de las veedurias ciudadanas, d) la ilegitimidad de las instancias de representación y gobierno, e) precarios logros alcanzados en el desarrollo de formas de asociatividad territorial (Ibíd., 2010: 11-13).

Del mismo modo, en los anteriores estudios colombianos se ha llegado a plantear que "la captura del Estado (CdE) se debe a las particulares instituciones -propias de la descentralización - las que, una vez introducidas en un contexto premoderno caracterizado por el clientelismo, el gamonalismo y el narcotráfico, terminan siendo capturadas y adaptadas a los intereses legales e ilegales dominantes en el municipio"(García y Revelo, 2010: 76) y que la entrada de recursos a los entes territoriales ha contribuido a que el clientelismo se trasladara a lo local, influyendo en la generación de prácticas clientelistas.

A continuación expondré algunas conceptualizaciones teóricas sobre clientelismo político desde algunas perspectivas antropológicas, politólogas y sociológicas. Sin embargo, como anuncié al inicio de este capítulo, el enfoque teórico de mi investigación intentará tomar distancia de dos modelos de análisis: el político cultural y el de mercado, para desarrollar una tercera línea teórica que toma como base las "redes sociales", y finalmente presentar la propuesta teórico-metodológica de "red clientelista" que utilizaré para identificar el fenómeno dentro del Resguardo de Cumbal.

Elementos y propiedades del concepto de clientelismo.

Cuando se habla de clientelismo se recurre a dos figuras principalmente: como un epifenómeno de la debilidad del Estado para administrar los conflictos de la sociedad y/o como institución informal que provee de recursos materiales e instrumentales a particulares. No obstante, al intentar contrastar estas posturas con estudios específicos, el interrogante de cómo se configura este fenómeno dentro de una sociedad, no es resuelto. Generando que los estudios sobre éste fenómeno se hayan tornado predecibles, en tanto han centrado su análisis alrededor de las figuras: "patrón-cliente", sus prácticas y discursos; pero han dejado de lado en algunos casos el papel de los mediadores en la relación del patrón y el cliente, y el mundo de conexiones entre estos actores. Para intentar superar esta problemática, se tomarán los conceptos de redes sociales, redes de resolución de problemas, redes de 
confianza, y su configuración en la acción política. En razón a que, "la acción social no tiene lugar nunca en un campo yermo y homogéneo, sino que requiere y produce sin cesar configuraciones especificas: comunidades, corporaciones, asociaciones, redes, que determinan y, literalmente, dan forma a la acción individual' (Escalante, 1995: 33).

Las relaciones clientelistas, las prácticas y los discursos, entendidas como una forma de acción política, no pueden ser entendidas conceptualmente sin ser atendidas las redes sociales como elementos que dan formas a las conexiones políticas entre los clientes y el patrón. No obstante, para defender esta posición, se expondrán las dos líneas teóricas sobre el clientelismo: el político-cultural y el de mercado, argumentando sus carencias teóricas y metodológicas, para finalmente exponer la herramienta conceptual a utilizar: "Las redes clientelistas"

Clientelismo político.

Se ha denominado "clientelismo político" a una forma clásica de intermediación política y social. La intermediación política es entendida como resultado de la deficiencia institucional en las nuevas democracias latinoamericanas. Para O’ Donnell (1996) "las nuevas poliarquias están a lo sumo pobremente institucionalizadas. Pocas parecen haber institucionalizado algo más que las elecciones, al menos en los términos que uno esperaría al mirar las viejas poliarquias. Pero las apariencias pueden engañar, dado que existen otras instituciones, si bien no las que a muchos de nosotros nos gustarian o que reconoceriamos fácilmente" (Auyero, 2001: 35), entre ellas el clientelismo.

Al considerar al clientelismo como una "institución informal" en términos de O' Donnell, implica que ésta sea conocida, aceptada y efectiva, así no cuente con personalidad jurídica ni identidad formal reconocible. Dicho de otra manera, asi el clientelismo sea fuertemente practicado y aceptado dentro de unas relaciones clientelares, éstas no necesitan ser aprobadas normativamente. Por el contrario estas relaciones están basadas en entendimientos y mecanismos informales, aun cuando existan altos niveles de compromiso y obligación por parte de los involucrados. Del mismo modo el clientelismo es entendido como una institución informal complementaria a las instituciones formales, sobre todo cuando proveen a los ciudadanos de mecanismos e información para acceder a ciertos beneficios otorgados por el Estado.

Sin embargo, considerar al clientelismo como un fenómeno producto de la debilidad de Estado, es insuficiente. Para Escalante y Lomnitz, el clientelismo no debe ser visto como una monstruosidad ajena a los mecanismos burocráticos y legales del Estado moderno, sino una consecuencia necesaria de ello, debido a que "la relación entre Estado y sociedad no es, en absoluto mecánica ni transparente,... "La sociedad no es una simple suma de individuos y no hay automatismo alguno en la acción de Estado". Por tanto la relación de los individuos con las instituciones públicas, la gestión de sus intereses, como el logro de su obediencia, requieren la operación de una maquinaria de intermediación" (Escalante, 1995: 34). Esto implica que la instauración del Estado moderno no acabó absolutamente con los intermediarios para ejercer sus operaciones, por el contrario, ha sido el clientelismo el fenómeno que da cuenta que la mediación entre la autoridad de Estado y los ciudadanos, sigue vigente. 
Para Escalante el problema se debe a que el aparato político y burocrático del Estado en Latinoamérica no ha tenido suficiente control y coordinación del conjunto de funciones politicas, administrativas y militares, obligando a las autoridades politicas a negociar su posición con los "notables locales". Esto provocó que la vida política se centrara en tramas regionales, pues el "control que podia tener la autoridad central sobre los funcionarios locales era muy precario" (Escalante, 1993: 102). Por otro lado, en Leal y Dávila esta debilidad politica del Estado se debe a la "poca capacidad para mediar institucionalmente en los conflictos de la sociedad" (Leal y Dávila, 1991: 23) sobre todo en las localidades, permitiendo así que estructuras clientelistas tomaran fuerza en aquellos grupos de notables locales.

Estos intermediarios locales y parcialmente autónomos han logrado sustentar su poder gracias a un marco informal de satisfacción de necesidades individuales, en el cual se establecen unas relaciones voluntarias, selectivas y cargadas de afecto, como también la consolidación de un contrato informal de intercambio de bienes por lealtad política. Para Auyero (2001) el clientelismo debe ser entendido como "el intercambio personalizado de favores, bienes y servicios por apoyo politico y votos entre masas y élites" (Auyero, 2001: 35), que perdura como una institución no formal, influyente, a veces oculta, y que no está destinada a desaparecer ni mantenerse en los márgenes. Para los anteriores autores la clave para entender el clientelismo radica, en que éste debe ser visto como un mecanismo tradicional de cooptación política o soporte electoral.

De igual forma, Gutiérrez y Dávila (2001) consideran al clientelismo como un "mecanismo no institucional de lealtades asimétricas, mediante el cual se intercambian bienes y servicios por apoyo electoral" (García y Revelo, 2010: 24) al interior de una amistad instrumental entre desiguales; desigualdad originada por la "diferencia de poder y control de recursos, en las que existe un patrón y cliente: el patrón proporciona bienes materiales, protección y acceso a recursos diversos y el cliente ofrece a cambio servicios personales, lealtad, apoyo político o votos" (Audelo, 2004: 127). No obstante, esta relación clientelar diádica (patrón-cliente) presenta grandes vacíos teóricos y metodológicos, pues no permite entender el mundo de conexiones políticas, sociales, económicas y culturales entre los políticos y su clientela.

Clientelismo y cultura política.

Algunos autores consideran que el clientelismo es más que un fenómeno político, es también "una forma de vida; una cultura y hasta una concepción de la sociedad (...) para las personas involucradas en entornos clientelistas, las reglas sociales que regulan el intercambio de favores, la fuerza de lealtades, las obligaciones reciprocas, las alianzas, etc.; son reglas por lo general, más poderosas y con mayor capacidad para determinar los comportamientos que las normas formales de derecho"(Ob. Cit., 2010: 30). Las prácticas clientelistas marcadas por esas -memorias múltiples, tradiciones heterogéneas, valores, creencias, experiencias sociales y personales acumuladas- son denominadas como cultura política. La cual está "enraizada en redes, hecha cuerpo en performances y actualizada y (re)procesada en prácticas concretas" (Auyero, 2001: 42).

Para esta perspectiva, es la cultura política la que permite otorgar un orden político a la sociedad. Esta construcción social de lo político, convierte a la cultura politica "el ámbito de las prácticas y las instituciones, conformadas a partir de la totalidad de la realidad social y 
que, históricamente, llegan a ser consideradas como apropiadamente politicas" (Escobar, Et. Al; 2001: 26). En este caso, ha sido el clientelismo un fenómeno que dota de sentido y unidad a las prácticas sociales. Incluso se ha llegado a plantear la existencia de una cultura clientelista en oposición a una cultura ciudadana. La primera regida por la influencia personal y en busca de intereses particularistas, y la segunda sometida por la ley y en busca del bien común. Sin embargo, nada de eso las hace incompatibles en la práctica, por el contrario dan lugar a complejas combinaciones en lo simbólico y material. De este modo "un individuo puede orientar su acción de acuerdo con las exigencias de la red o la configuración que sea, sin dejar de cumplir con la ley; (...) puede ser ciudadano sin dejar de pertenecer a una clientela" (Escalante, 1993: 33).

No es posible identificar una cultura política por fuera de la acción política; como tampoco es posible identificar una cultura clientelista por fuera de los recursos politicos involucrados: favores, servicios y lealtad. Por consiguiente, las prácticas clientelistas no son sólo resultado de una serie de valores, normas, tradiciones o sintesis de una forma de vida; sino también son efecto de los recursos políticos y económicos disponibles. Más adelante se expondrá que tan necesario son estos recursos para movilizar servicios, lealtades, confianza y apoyo electoral.

Clientelismo de mercado.

La tercera línea teórica y complementaria de las anteriores, es la del "clientelismo de mercado". Que tiene como característica única la base económica prestada por el Estado. Para Leal y Dávila "el moderno clientelismo politico mercantil es alimentado por el Estado y sustentado en el antiguo y difundido valor de las lealtades" (Leal y Dávila, 1991: 47). Éste tipo de clientelismo se construye dentro de relaciones articuladas horizontal y verticalmente ${ }^{2}$, donde el intercambio de favores se hace en base al control de los recursos oficiales. Los recursos y servicios que se distribuyen dentro de estas relaciones clientelares son: "los instrumentales (políticos y económicos) y los sociables o expresivos (promesas de lealtad y solidaridad" (Auyero, 2001: 38). Estos recursos se distribuyen entre los "patrones, mediadores y clientes" ${ }^{3}$, quienes establecen relaciones contractuales de tipo informal. Lo característico en el clientelismo de mercado es "su carácter local y particularista de la representación que ofrece" (García y Revelo, 2010: 25). En el clientelismo de mercado los politicos hacen uso particularista de recursos públicos, sobre todo en el control de la distribución de los cargos burocráticos del Estado.

Para esta noción de clientelismo, es el intercambio de bienes y servicios por apoyo político sustentado en la base económica prestada por el Estado, el pilar para entender su desarrollo dentro de un grupo social. Sin embargo, no es absolutamente acertado el presuponer que son los favores, bienes y servicios lo que provocan el apoyo politico y los votos. Para Auyero (2001) es confundir la circulación de estos elementos, con los principios generadores del clientelismo.

En consecuencia, es insuficiente teórica y metodológicamente considerar al clientelismo como una institución informal de intermediación política que suple el vacío de la debilidad institucional del Estado, o como un tipo de prácticas que nacen de una cultura política dominante y de una cultura clientelista, como también es limitado considerarlo como un mero intercambio de favores, bienes y servicios por apoyo político entre patrones, mediadores 
y clientes. Pues no permite establecer el mundo de conexiones entre las diferentes relaciones entre sus actores, las prácticas, discursos, concepciones culturales, identidades individuales y colectivas que se ponen en juego en estos intercambios. Por lo que es necesario vincular en este análisis los conceptos de redes sociales, redes de confianza y redes de solución de problemas, y cómo estas redes se configuran dentro de la acción política, para así entender la configuración del clientelismo en una sociedad.

Red clientelista.

El clientelismo en términos de Durston (2005) no debe tomarse como un simple intercambio de favores por votos. Sino como "un conjunto de relaciones personales, con elementos de afecto y reciprocidad difusa, operando como una extensión de las redes de ayuda mutua, que cabe plenamente en el marco conceptual del capital social, como una forma vertical, asimétrica de capital social individual" (Ibíd., 2005: 7-8) y que se retroalimenta con "actitudes de confianza en un círculo virtuoso de acumulación de capital social, sea de propiedad de un individuo o de una colectividad" (Ibíd., 2005: 5). El clientelismo por tanto se define como una forma de capital social ${ }^{4}$, en tanto les permite a los individuos el intercambio material y simbólico en una red de relaciones con un grado de institucionalidad. Sin embargo, el capital social se vuelve nulo cuando se disminuye la capacidad de una red de movilizar los recursos del mismo.

En este sentido, es el concepto de redes sociales el que permite comprender el desarrollo del clientelismo, pues éstas "ofrecen el control de cierto tipo de recursos y cuentan siempre con mecanismos de inclusión y de exclusión que les permiten, cualquiera que sea su naturaleza, servir de referencia para las identidades de los individuos (...) son forma de vinculación socialy de reconocimiento, que producen orden por medio de la confianza" (Escalante, 1995: 35). El clientelismo depende de las redes sociales por su capacidad de movilizar recursos, su acción vinculativa y la producción de confianza, siendo todas estas esenciales para el desarrollo de la política en el sentido que les permite a los políticos el mantenimiento de un grupo electoral y a los ciudadanos su inclusión en las politicas públicas.

Las redes sociales en términos de Granovetter (1973) se componen de vínculos, éstos pueden ser fuertes, débiles o ausentes. Los vínculos se miden de acuerdo a la "influencia $e$ información, la oportunidad de movilidad y la organización comunitaria (...) la fuerza de un vinculo es una (probablemente lineal) combinación del tiempo, la intensidad emocional, intimidad (confianza mutua) y los servicios reciprocos que caracterizan a dicho vínculo" (Oyarzun, Et. Al; 2011: 119-132). Por lo tanto, un vínculo fuerte se presenta cuando hay una alta concentración de influencia, información, confianza y reciprocidad. Por el contrario, un vínculo débil se presenta cuando hay una baja concentración de influencia, confianza y reciprocidad. Dependiendo del vínculo -fuerte o débil- entre la red y el patrón se definen las relaciones de reciprocidad; es decir, cuanta más alta sea la confianza, la lealtad, la influencia bilateral, es más probable el apoyo político y la inclusión de estas redes en los beneficios. Por lo tanto el grado de eficacia de los vínculos dentro de las redes y de éstas con los políticos, no debe pasar por alto en el análisis de las relaciones contractuales de intercambio instrumental y de sociabilidad del clientelismo. 


\section{Conclusiones.}

Al igual que la acción social y la acción política, el clientelismo no es un fenómeno homogéneo ni limitado, sino un fenómeno social que produce y requiere de redes para su configuración. Siguiendo este lineamiento no es erróneo hablar de "redes clientelistas", entendidas como una forma de sociabilidad en las que se involucran tres actores: patrón (político), mediador (grupos bisagra o de articulación) y cliente (ciudadanos o grupos organizados).

Primero, esta red clientelista no es del todo vertical ni horizontal, en tanto hay ejercicios de dominación y subordinación por parte de los tres actores. Segundo, el funcionamiento de la red depende exclusivamente del tipo de recursos intercambiados (información, favores y apoyo electoral) y el tipo de vínculos entre los participantes (lazos de confianza y reciprocidad). Por lo tanto, cuando se presume que "los juegos políticos de "pirámide" o de "red" no necesariamente son bilaterales" y que" el clientelismo puede presentarse entre individuos de igual status social donde la reciprocidad, sobra notarlo, suele ser violada por una de las partes" (Gómez, 1984: 42), se habla justamente de que el clientelismo no es absolutamente jerárquico, y que si la reciprocidad es violada se debe a la existencia de un vínculo débil entre patrón, intermediario y cliente, provocado por la falta de confianza. Anteriormente se mencionó la importancia de la confianza, ya que sin un minino de confianza no se puede desarrollar el clientelismo, ¿cómo participar en una red clientelista sin una mínima confianza en obtener algún tipo de recompensa? Tercero, la red clientelista no sólo satisface necesidades que la estructura legal no resuelve, sino que proporciona vías de movilidad social a quienes estarian excluidos por los caminos tradicionales de ascenso personal. Y cuarto, las relaciones que se establecen dentro de la red son estratégicas, selectivas, competitivas, jamás permanecen estáticas, son totalmente móviles, y actúan de acuerdo a los beneficios que estas garanticen. Estas relaciones se potencializan o se dificultan según la debilidad o fortaleza de los lazos sociales y los recursos que éstos movilizan. Para Auyero los "lazos que vinculan a los mediadores con su círculo intimo son densos e intensos; y los lazos con el círculo exterior son más ocasionales e intermitentemente activados" (Auyero, 2001: 109). Es decir, los lazos se vuelven débiles en los círculos externos a la red donde los vínculos de amistad o de parentesco se vuelven ficticios, y se fortalecen en los círculos íntimos donde los lazos son más cercanos y cotidianos.

Para observar el funcionamiento y la capacidad de los lazos sociales y su relación con las redes políticas, es necesario recurrir a dos conceptos: Redes de resolución de problemas y Redes de confianza. Las primeras funcionan al interior de redes de parentesco y vecindad, son el resultado de múltiples estrategias de sobrevivencia en poblaciones marginales y actúan como un sistema de seguridad social ${ }^{5}$. Autores como Lomnitz (1975), Friedman y Salguero (1988), las han denominado como redes informales de reciprocidad o ayuda mutua, que permiten la sobrevivencia material y la constitución de entramados culturales y simbólicos. Los bienes y servicios intercambiados en una red de reciprocidad son: a) información, b) asistencia laboral, c) prestamos, d) servicios y e) apoyo moral. En el análisis de Auyero se proponen cuatro redes de resolución de problemas: 1) Las unidades básicas,2) la iglesia,3) los referentes políticos (municipalidad), y 4) los planes estatales de ayuda (programas asistencialistas), que actúan como lazos sociales y como fuente de recursos para la sobrevivencia y que han sido fuertemente instrumentalizadas por las redes clientelistas.

I

AGO.USB Medellín-Colombia $\quad$ V. 12 №2 PP. 214- 547 Julio-Diciembre 2012 ISSN: 1657-8031 
Cuando las redes políticas entran en contacto con las redes informales de reciprocidad, las estrategias de sobrevivencia se constituyen en "avenidas de participación" o enclaves de acceso a recursos estatales y/o a auxilios otorgados por un partido político. Las redes politicas son "un conjunto de contactos regulares o conexiones sociales similares entre individuos o grupos en los cuales, al menos uno de ellos es miembro de un partido politico o un funcionario estatal" (Ibíd., 2001: 100). Estos miembros de anclaje se conocen como "mediadores" y son los que permiten una conexión entre las redes de resolución de problemas y las redes políticas. Su función es canalizar "recursos, bienes y servicios del partidos o de una estructura estatal particular hacia el espacio de la comunidad a través de una organización partidaria particular" (Ibíd., 2001: 104), como también canalizar "el apoyo desde los clientes a la persona que controla los recursos" (Ibíd., 2001: 98). Para Auyero el poder del mediador se deriva de su posición en la red, y dicho poder consiste en la monopolización de la información y en su capacidad de obstruir o facilitar el flujo de demandas, favores, bienes y servicios, desde o hacia una comunidad. El mediador utiliza tres recursos: las carencias materiales de comunidades, su conocimiento e influencia en ellas, la ineficiencia administrativoburocrática y su contacto directo con el patrón.

Por otro lado las redes de confianza, los recursos que éstas manejan y sus conexiones con la política, son analizados por Charles Tilly (2010) en su libro "Democracia". En primer lugar, las redes de confianza consisten en "conexiones interpersonales ramificadas, que consisten en fuertes vínculos, dentro de los cuales la gente pone en práctica recursos, empresas valiosas, consecuenciales y de largo plazo, aun a riesgo de errores, fallos o a la poca destreza de los demás" (Ibíd., 2010: 116). Los elementos que las caracterizan son: 1) las conexiones en red, 2) lazos vigorosos entre sus miembros, 3) conformación de empresas colectivas de ayuda mutua y 4) confianza ante posibles riesgos de fallos individuales.

La integración de las redes de confianza en la política pública les permite a sus integrantes tener acceso a recursos políticos y a las redes clientelistas la conformación de una base electoral. Para Tilly los recursos políticos incluyen beneficios y castigos que influyen en la participación de las personas en la política. Éstos se dividen en: Coerción, capital y compromiso. La coerción es definida como "los medios de acción concertados que por lo general causan pérdidas o daños a personas, posesiones o relaciones que sustentan a los actores sociales", el capital es considerado como aquellos recursos tangibles, transferibles, que pueden producir ganancia y ser ejecutables, y el compromiso significa "las relaciones entre personas, grupos, estructura o posiciones que promueven tenerse en cuenta mutuamente (Ibíd., 2010: 122 -123)".

También, en estas redes los intermediarios juegan un papel clave en las conexiones políticas entre las redes de confianza y la política pública. Hay dos tipos de intermediarios parcialmente autónomos: a) las entidades formales con intereses putativos (sindicatos, asociaciones, iglesias) y b) elites locales con influencia en el gobierno. Los primeros pueden representar públicamente los intereses colectivos y los segundos suelen subordinar las redes a empresas meramente electorales. Sin embargo, Tilly (2010) propone que estas redes de confianza pueden ser integradas a la política pública, siempre y cuando se haga por medio de acuerdos controlados por el Estado y se creen garantías para sus empresas colectivas, valiosas y de largo plazo. De acuerdo a lo anterior, el clientelismo implica la integración

AGo.USB Medellín-Colombia V. $12 \quad N^{\circ} 2$ PP. 214- 547 Julio-Diciembre 2012 ISSN: 1657-8031 
indirecta de las redes de confianza en la política pública y el fortalecimiento de la autonomía y el poder de los intermediarios. De igual manera las redes clientelistas les permiten a los mediadores sancionar a aquellos que intenten escapar del contrato y/o premiar aquellas relaciones de amistad y confianza para así consolidar el apoyo electoral.

Auyero y Tilly proponen por tanto hacer una distinción entre intermediario y mediador. El primero se establece como una institución formal o informal (sindicato- poder autónomo) de intermediación entre el Estado y los ciudadanos; por el contrario el mediador es una pieza de anclaje entre el patrón y el cliente, es el que crea el contacto y distribuye los recursos otorgados por el patrón.

El clientelismo debe ser entendido en función de las redes sociales. Primero, porque permiten identificar un mundo de conexiones que se generan entre los diferentes actores, y los recursos (materiales y simbólicos) que se movilizan dentro de estas conexiones. Segundo, por su acción vinculativa-al proporcionar vías de movilidad social- siempre cuando existan lazos de confianza (fuerte o débil). 


\section{Referencias.}

Audelo, J. (2004). ¿Qué es el clientelismo?: Algunas claves para comprender la política en los países en vías de consolidación democrática. Estudios sociales Universidad de Sonora, 125-142.

Auyero, J. (2001). La politica de los pobres: Las prácticas clientelistas del peronismo. Buenos Aires: Ediciones Manantial. Buenos Aires: Ediciones Manantial.

Bourdieu, P. (2001). Poder, derecho y clases sociales. Barcelona: Editorial Desclée.

Chaves, M., \& Hoyos, F. (2011). "El estado en las márgenes y las márgenes como estado: transferencias económicas y gobiernos indígenas en Putumayo". La multiculturalidad estatalizada: indígenas, afrodescendientes y configuraciones de estado, 115-134.

Durston, J. (Marzo de 2005). El clientelismo político en el campo chileno (primera parte): La democratización cuestionada. Obtenido de ciencias sociales online: http://www.uvm.cl/csonline/2005_1/pdf/clientelismo.pdf.

Escalante, F. (1993). "El poder de los intermediarios". Ciudadanos imaginarios, 97-109.

Escalante, F. (1995). Clientelismo y ciudadanía en México: Apuntes sobre la conceptualización de las formas de acción política. 31-39.

Escobar, A., Alvaraez, S., \& Dagnino, E. (2001). Lo cultural y lo político en los movimientos sociales latinoamericanos. Bogota: Taurus-Icanh.

Garcia, M., \& Revelo, J. (2010). Estado alterado: clientelismo, mafias y debilidad institucional en Colombia. Bogota: Coleccion de justicia.

Gomez, H. (1984). Lo patológico y lo democrático del clientelismo. Obtenido de http://www.nuso.org/upload/articulos/1213_1.pdf.

Gutierrez, F. (2010). 25 años de la descentralizacion en Colombia. Bogota: KAS.

Leal, F., \& Davila, D. (1991). Clientelismo, el sistema político y su expresión regional. Bogota: Tercer Mundo Editores.

Meneses, E. (2002). La política nasa y el clientelismo: en el municipio de Páez, Cauca. Revista Colombiana de Antrologia, 105-130.

O`Donnell, G. (2004). La democracia en América Latina: Hacia una democracia de ciudadanas y ciudadanos. Buenos Aires: PNUD.

O`Donnell, G. (2007). Democracia/Estado/Ciudadanía: Hacia un Estado de y para la Democracia en América Latina. Lima: PNUD. 
Oyarzun, I., Vasquez, A., \& Orellana, C. (2012). Redes sociales como condición necesaria para el clientelismo Político. Revista Lider, 119-132.

Romero, J. (2007). Clientelismo, patronazgo y justicia electoral en México: Una lectura institucionalista. Mexico D.F.: PNUD y Universidad Autonoma Metropolitana.

Tilly, C. (2010). Democracia. Madrid: Akal.

418

AGO.USB Medellín-Colombia V. $12 \quad N^{\circ} 2$ PP. 214- 547 Julio-Diciembre 2012 ISSN: 1657-8031 
${ }^{2}$ Vertical al ser considerado el clientelismo como un arreglo jerárquico y horizontal al incluir dentro de sus redes a asociaciones locales o grupos populares organizados.

${ }^{3}$ Actores desarrollados en Lomnitz $(1975,1988)$ y retomados en Auyero $(1997,2001)$, Durston (2005).

${ }^{4}$ El capital social es entendido en Bourdieu como "la totalidad de los recursos potenciales o actuales asociados a la posesión de una red duradera de relaciones más o menos institucionalizadas de conocimiento y reconocimiento mutuos. Expresado de otra forma, se trata aqui de la totalidad de recursos basados en la pertenencia a un grupo" (Bourdieu, 2001:148).

${ }^{5}$ Las estrategias de sobrevivencia han sido estudiadas por: Mingione (economía popular); Lomnitz, Friedman, Salguero y Auyero (redes informales de reciprocidad o ayuda mutua). 